\title{
To Evaluate the Effect of Solvents and Different Relative Humidity Conditions on Thermal and Rheological Properties of Microcrystalline Cellulose 101 Using METHOCEL ${ }^{\text {TM }}$ E15LV as a Binder
}

\author{
Moksh Jagia, ${ }^{1}$ Maitri Trivedi, ${ }^{2}$ and Rutesh H. Dave ${ }^{1,3}$
}

Received 22 July 2015; accepted 25 September 2015; published online 19 October 2015

\begin{abstract}
The solvent used for preparing the binder solution in wet granulation can affect the granulation end point and also impact the thermal, rheological, and flow properties of the granules. The present study investigates the effect of solvents and percentage relative humidity $(\mathrm{RH})$ on the granules of microcrystalline cellulose (MCC) with hydroxypropyl methyl cellulose (HPMC) as the binder. MCC was granulated using $2.5 \% \mathrm{w} / \mathrm{w}$ binder solution in water and ethanol/water mixture $(80: 20 \mathrm{v} / \mathrm{v})$. Prepared granules were dried until constant percentage loss on drying, sieved, and further analyzed. Dried granules were exposed to different percentage RH for $48 \mathrm{~h}$ at room temperature. Powder rheometer was used for the rheological and flow characterization, while thermal effusivity and differential scanning calorimeter were used for thermal analysis. The thermal effusivity values for the wet granules showed a sharp increase beginning $50 \% \mathrm{w} / \mathrm{w}$ binder solution in both cases, which reflected the over-wetting of granules. Ethanol/water solvent batches showed greater resistance to flow as compared to the water solvent batches in the wet granule stage, while the reverse was true for the dried granule stage, as evident from the basic flowability energy values. Although the solvents used affected the equilibration kinetics of moisture content, the RHexposed granules remained unaffected in their flow properties in both cases. This study indicates that the solvents play a vital role on the rheology and flow properties of MCC granules, while the different RH conditions have little or no effect on them for the above combination of solvent and binder.
\end{abstract}

KEY WORDS: end point; granulation; powder rheology; relative humidity; thermal effusivity.

\section{INTRODUCTION}

In recent years, granulation has been studied extensively. With tablets and capsules being the most common and convenient solid oral dosage forms, an optimally designed granulation technology can act as a tremendous tool for minimizing the variability in the batches, and hence diminishing the risk of poor quality (1). Over the past few decades, the practice of pharmaceutical granulation, especially wet granulation, has evolved scientifically and technologically. Wet granulation is defined as the process of mixing the drug and the filler powders together, and subsequently, wetting them by a binder solution to obtain agglomerates such that the individual particles can still be differentiated (2). The type and the concentration of the binder solution used plays a critical role in the wet granulation end point determination $(3,4)$ and also on the various physical attributes of the tablets $(5,6)$ such as hardness, friability (7), dissolution time (8), disintegration

\footnotetext{
${ }^{1}$ Division of Pharmaceutical Sciences, Arnold \& Marie Schwartz College of Pharmacy and Health Sciences, Long Island University, Brooklyn, New York 11201, USA.

${ }^{2}$ Norwich Pharmaceuticals, Norwich, New York 13815, USA.

${ }^{3}$ To whom correspondence should be addressed. (e-mail: rutesh.dave@liu.edu)
}

time (9), compressibility, and the content uniformity of the tablets (10).

End point in wet granulation refers to the point and the appropriate time at which the granules reach the desired stage of similar mean particle size distribution, density, and homogeneity (11) irrespective of the processing variables such as the impeller or chopper speed and the binder addition rate (12). Although there is no generalized method of end point detection in wet granulation, a few methods like NIR spectroscopy (13), torque measurements (14), and power consumption (15) have been used successfully to date. Recently, thermal effusivity measurements have come up as a novel tool to determine the end point of wet granulation by measuring powder energies and thermal properties $(16,17)$.

Microcrystalline cellulose (MCC) is one of the most commonly used pharmaceutical excipient in the production of tablets and capsules. It can be used both as a diluent or binder in the wet granulation and direct compression processes. Binders play an important role in determining the hardness and friability of the tablets (18). HPMC cellulose ethers serves as a great binder and adhesive in the wet granulation step for the production of the immediate and sustained release tablets $(19,20)$. The viscosity and surface tension of the binder solution are known to impact the granulation mechanism depending on the capillary and viscous forces (21). 
The flow properties of the granules formed after wet granulation are greatly influenced by the environmental conditions, such as humidity and temperature, under which the granules are stored in hoppers, transported, formulated, mixed, compressed, and packaged $(22,23)$. So, the significance of understanding the powder rheological properties with an outlook to obtain the desired reproducible end results cannot be negated $(24,25)$. The traditional methods like angle of repose (26), bulk and tapped density (27), Carr's compressibility index (28), and Hausner's ratio (29) have long been used for the powder flow characterization, but the lack of reproducibility and predictability paved ways to the need for novel methods. With the advancement in technology, new methods such as shear cell $(30,31)$, avalanche testing (32), cohesivity determination (33), torque rheometer (34), penetrometry (35), atomic force microscopy (36), and powder rheometer (37) have been successfully used, but no specific method has still been standardized for the assessment of powder flow properties. Powder rheometer has shown reproducible and acceptable results in measuring the dynamic, bulk, and shear properties of powders $(38,39)$.

The aim of the above-mentioned study was to evaluate the use of the thermal effusivity probe and the freeman technology (FT4) powder rheometer, as joint tools in determining the effect of solvents on the optimum wet granulation end point of the MCC granules, formed with hydroxypropyl methyl cellulose (HPMC) as a liquid binder in water and ethanol/water (80:20) solvent systems. Besides this, the primary purpose of the research was to assess the effect of the solvents used above on the rheological properties of the wet and dried granules using the powder rheometer. In addition to this, it focuses on the impact of different levels of humidity on the flow properties of the dried granules, for the above combination of solvent and binder. The above-mentioned study shall help the formulation scientists in the selection of suitable solvents and optimum storage conditions for the granules, in terms of their rheological and flow property values. These values can, in turn, help in assessing the stability of the granules when exposed to the different humidity environment, which always remains an area of concern for the pharmaceutical industry.

\section{MATERIALS AND METHODS}

\section{Materials}

Microcrystalline Cellulose (Avicel® PH-101 NF, lot\#: P113825474 FMC Biopolymer, Philadelphia, PA) was used as given. Hydroxypropyl methyl cellulose (METHOCEL TM E15 Premium LV lot\# VL23012406 a trademark of the Dow Chemical Company, Midland, MI) was used as a binder solution with deionized water (Barnstead Nanopure - Thermo scientific system, Waltham, MA) collected below $13 \mathrm{~m} \Omega / \mathrm{cm}$ and ethyl alcohol (190 proof ACS/USP grade, lot\# C1202101, Pharmco Products Inc., Brookfield, CT) as solvents.

\section{Small-Scale Preparations}

Ten grams of MCC 101 was granulated with varying (5, $10,15,20,25,30,35,40,45,50,55,60)$ percentage $(\% w / w)$ concentration of HPMC E15 $(2.5 \% w / w)$ as binder using water and ethanol/water (80:20) mixture as solvents in a mortar and pestle. Subsequent thermal effusivity measurements were conducted using the thermal conductivity (TC) probe, Mathis instrument. The tentative end point of wet granulation was determined for both granulating fluids.

\section{Preparation of Granules}

To reach to an even more precise conclusion regarding the wet granulation end point, a $( \pm 2.5 \%)$ of the end point binder solution was carried out in both cases. Wet granulation was carried out by a cuisinart mixer (East Windsor, NJ) on a batch size of $700 \mathrm{~g}$ of MCC 101 with $42.5 \%, 45 \%, 47.5 \%, 50 \%$ $w / w$ binder solution (in case of water) and $45 \%, 47.5 \%, 50 \%$, $52.5 \% \mathrm{w} / \mathrm{w}$ binder solution (in the case of ethanol/water mixture). The granulating fluid was added for a period of $30 \mathrm{~s}$, and the blade speed was maintained between 40 and $60 \mathrm{rpm}$ with the total process of wet granulation being carried out for $3 \mathrm{~min}$. The wet mass, thus obtained after subsequent addition, was subjected to rheometer for further analysis. The remaining wet mass was passed through sieve $\# 12$; dried at $60^{\circ} \mathrm{C}$ until the percentage moisture content was reduced to $3-5 \%$; and finally, the dried granules were collected for further assay. Percentage moisture content was established using loss on drying (Ohaus, MB 200, Pinebrook, NJ) measurements. The granules thus collected for each batch were subjected to rheological characterization. All the experiments and the powder characterization were done in triplicates to measure reproducibility, and the standard deviation obtained was $<10 \%$.

\section{Thermal Effusivity Measurements}

The thermal effusivity measurement was carried out using the non-destructive, rapid testing c-therm (formerly Mathis instrument, Canada) $\mathrm{ESP}^{\mathrm{TM}}$ thermal conductivity (TC) probe. Samples following the wet granulation were placed in direct contact with the sensor surface, so as to provide the maximum surface area contact for efficient results. The TC probe utilizes the principle of the change in the voltage drop of the sensor element as a result of the interfacial temperature change between the sample and the sensor due to the heat generated by the sensor. Thermal effusivity is a function of the thermo-physical properties of the material given by the following equation:

Effusivity $=\sqrt{k \rho C_{p}}$

Where

\section{$k$ Thermal conductivity $(\mathrm{W} / \mathrm{m} \cdot \mathrm{K})$ \\ $\rho$ Density $\left(\mathrm{kg} / \mathrm{m}^{3}\right)$ \\ $C_{p}$ Heat capacity $(\mathrm{J} / \mathrm{kg} \cdot \mathrm{K})$}

An equal volume-filled spatula of the sample (2-3 g) obtained from different locations of the above-mentioned prepared wet granules of MCC 101 with $42.5 \%, 45 \%$, $47.5 \%, 50.0 \% w / w$ binder solution (in case of water) and $45 \%, 47.5 \%, 50.0 \%, 52.5 \% \mathrm{w} / \mathrm{w}$ binder solution (in the case of ethanol/water mixture) was subjected to the thermal effusivity testing. The experiments were conducted in 
triplicates, so as to define the specific wet granulation end point for each batch.

\section{Preparation of Humidity-Controlled Environment}

The end point dried granules for both cases were treated with a chemically controlled humidity environment for a period of $48 \mathrm{~h}$ by the use of the binary saturated aqueous solutions in which the solute is highly non-volatile. Saturated salt solution was prepared as a slushy mixture with distilled water and chemically pure salt enclosed in a sealed glass or metal chamber. The humidity chamber thus prepared was inspected for the required relative humidity using a digital VWR Hygrometer. Given that a saturated salt solution imparts only one relative humidity at a particular temperature (40), different salts were selected to provide three different relative humidities of $22.5 \%, 53.0 \%$, and $75.0 \%$ at room temperature $\left(25^{\circ} \mathrm{C}\right)$. The saturated salt solution of potassium acetate, with an equilibrium relative humidity of $(22.51 \pm 0.32)$, magnesium nitrate $(52.89 \pm 0.22)$, sodium chloride $(75.29 \pm 0.12)$ were used to mimic the three different relative humidity environments at $25^{\circ} \mathrm{C}$, i.e., room temperature $(40,41)$.

\section{Powder Characterization Using Rheometer}

The wet mass obtained after granulation, dried granules, and the humidity-treated dried granules were all subjected to the rheological characterization using freeman technology (FT4) rheometer (Worcestershire, UK). The FT4 powder rheometer is a universal powder tester that can measure the dynamic, bulk, and shear properties of powders and granules. The instrument was calibrated for force, torque, height, and rotational and linear velocities prior to use. A conditioning cycle was generally used to establish a homogenized low stress packing in the powder bed and also to remove any precompression or excess air by exerting a slicing action of the blade downward, followed by an upward traverse which gently lifts the powder and drops it over the blade, each particle coming to rest behind it. After the conditioning cycle, the dynamic properties viz basic flowability energy (BFE), specific energy (SE), and aeration energy (AE), bulk properties viz compressibility and permeability, shear properties viz wall friction angle (WFA), and shear stress were measured (42).

\section{BFE Measurement}

In accordance with the standard operating procedure, a $50 \mathrm{~mm} \times 160 \mathrm{~mm}$ of the cylindrical split vessel assembly was clamped on the platform of the rheometer and filled with the required sample to be assayed. The BFE is the energy required to establish a particular flow pattern in a conditioned precise volume of the powder. The 48-mm diameter twisted blade moving with a $-100 \mathrm{~mm} / \mathrm{s}$ tip speed and rotating at a $-5^{\circ}$ helix was used to establish this flow pattern by the downward anticlockwise motion, resulting in a compressive relatively high stress flow mode in the powder sample. The amount of the work done by the blade in moving from top to bottom of the vessel by overcoming the resistance to the movement of the blade was found by integrating the area under the force-distance profile and was denoted as the BFE of the sample (43).
Specific Energy Measurement

The specific energy is calculated from the energy required to establish a particular flow pattern in a conditioned precise volume of the powder. The $48-\mathrm{mm}$ diameter twisted blade that was used to measure the BFE when returning back from the bottom to the top was used to establish the same flow pattern, but by the upward clockwise motion of the blade moving at $100 \mathrm{~mm} / \mathrm{s}$ and rotating at $+5^{\circ}$ helix. This resulted in the gentle shearing and lifting mode of displacement. The energy used was then divided by the split mass to obtain the specific energy. Due to this low stress ambience, cohesion is the most influential property.

\section{Permeability Measurement}

Permeability is a measure of how easily the air passes through a powder at increasing bulk stress. Pressure drop (PD) is used to characterize the effect on permeability. For the PD measurement, a $50 \mathrm{~mm} \times 85 \mathrm{ml}$ of the cylindrical vessel was clamped on the platform of the rheometer with an aerated base at the bottom equipped with a constant air supply of $10 \mathrm{~mm} / \mathrm{s}$. In this test module, the conditioned powder sample was subjected to a normal stress range of 1 to $15 \mathrm{kPa}$ with the aid of a vented piston. Air pressure drop across the powder bed (i.e., resistance to air flow through the powder bed) was measured for the applied normal stress by using the given equation:

$k=\frac{q \mu L}{\Delta P}$

Where

$k \quad$ Permeability $\left(\mathrm{cm}^{2}\right)$

$q$ Flux, or air flow rate $(\mathrm{cm} / \mathrm{s})$

$L \quad$ Length of powder bed

$\Delta P$ Pressure drop across the powder bed (mbar)

\section{Compressibility Measurement}

Compressibility is a measure of changes in the powder's density owing to the direct application of a consolidating load. In this test, a vented piston was used to compress the conditioned sample contained in a $50 \mathrm{~mm} \times 85 \mathrm{ml}$ cylindrical split vessel under increasing normal stress, which was applied for a defined period to equilibrate with the powder bed. Compressibility was then calculated based on the change in the compressed bulk density (CBD) as a measure of the percentage change in the volume calculated as follows:

Compressibility $=$ percentage change in volume after compression $(\%)$ Bulk density $=$ split mass $/$ volume after compression $(\mathrm{g} / \mathrm{ml})$

\section{Aeration Energy/Ratio Measurement}

For aeration testing, a $50 \mathrm{~mm} \times 260 \mathrm{ml}$ vessel was clamped to the platform with an aerated base at the bottom, and the 
conditioned powder sample was checked for the variation in the flow properties due to an increasing air supply ranging from 2 to $10 \mathrm{~mm} / \mathrm{s}$. The twisted blade with a tip speed of $100 \mathrm{~mm} / \mathrm{s}$ was used, and the changes in the aeration ratio and aeration energy was calculated using the formula:

Aeration ratio $(\mathrm{AR})=\operatorname{Energy}(\operatorname{air}$ velocity $0 \mathrm{~mm} / \mathrm{s}) /$ Energy $($ air velocity $n)$ Aerated energy $\left(\mathrm{AE}_{n}\right)=$ Energy $($ air velocity $n)(\mathrm{mJ})$

Aeration energy refers to the energy required to transform the powder bulk in to fluidized bed in which powder behaves as a fluid.

\section{Wall Friction Measurements}

Wall friction refers to the friction between the powder sample and the equipment surfaces. In this test module, a $50 \mathrm{~mm} \times 85 \mathrm{ml}$ cylindrical split vessel was mounted on a serrated base placed on the rheometer platform, and the conditioned sample was subjected to varying consolidation stresses using the wall friction assembly (wall disc made of 316 stainless steel, having a roughness average of $1.2 \mu \mathrm{m}$ ), which operates on the principle of inducing both the vertical and the rotational stresses. The wall friction angle was determined by plotting each of the steady state shear stress (rotational stress) values against their corresponding normal stresses (vertical stress) and the effect of the powder flow properties against the material in contact studied. This parameter computes the force required to move a solid bulk against the specific wall material (44).

$\phi=\tan ^{-1}\left(\tau_{w} / \sigma_{w}\right)$

where, $\tau_{w}$ and $\sigma_{w}$ are the shear and the normal stress on the wall material, respectively.

\section{Shear Cell Analysis}

The shear cell analysis employed the use of the $50 \mathrm{~mm} \times 85 \mathrm{ml}$ cylindrical split vessel mounted on a serrated base similar to the wall friction test. The conditioned powder sample after pre consolidating with the vented piston was over consolidated with respect to the normal stress applied during shearing. This was achieved by reaching a critical consolidation level at steady state flow and then reducing the normal stress for shearing using the shear cell module. The shear stress was increased until the bed failed or sheared, and the maximum shear stress was observed, which was denoted as the point of incipient failure or the yield point. Each of the incipient failure points were then plotted against their corresponding normal stresses to give the yield loci (44).

These yield loci utilizing the Mohr's circle analysis as shown in (Fig. 1) (45), acted as the basis of parameters obtained during shear test such as: cohesion, unconfined yield strength (UYS) (measure of the frictional and cohesion forces acting between powder particles at different degrees of consolidation), major principal stress (MPS)

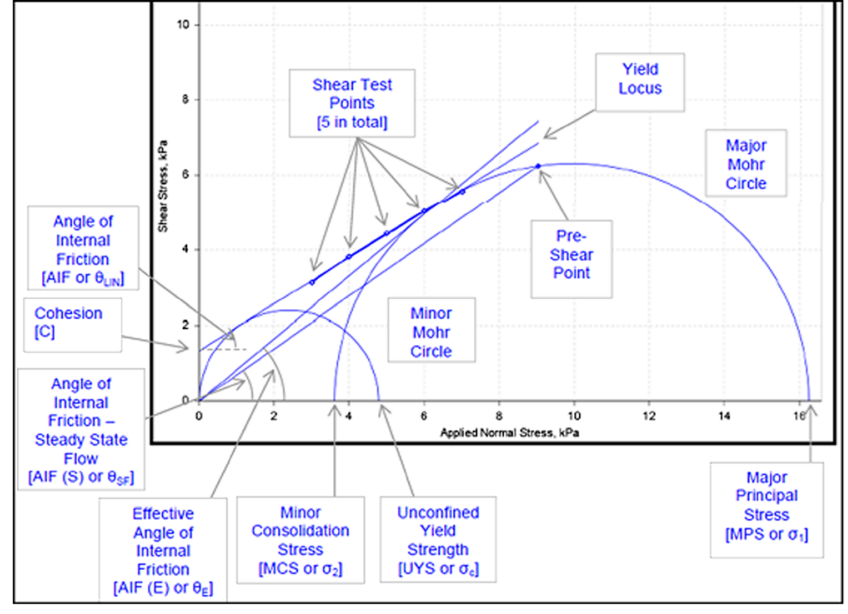

Fig. 1. Shear Cell Analysis

(pressure applied to consolidate the powder), and flow function $\left(\mathrm{ff}_{\mathrm{c}}\right)$. The value for $\mathrm{ff}_{\mathrm{c}}$ is calculated as:

$\mathrm{ff}_{\mathrm{c}}=\mathrm{MPS} / \mathrm{UYS}$

The measurements carried out in the shear test were based on the Jenike's assumptions regarding the flow measurements of bulk solids. Hence, the data obtained was analyzed and interpreted in the same way as that obtained from a Jenike shear tester $(46,47)$.

\section{Differential Scanning Calorimetry}

Differential scanning calorimetry (DSC) study was carried out using the Q100 (TA Instruments, New Castle, DE) with nitrogen $(50 \mathrm{ml} / \mathrm{min})$ as purge gas. The instrument was first calibrated with indium. The experiments were performed in hermetically sealed aluminum pans and the mass of each of the sample was $7 \pm 1.5 \mathrm{mg}$. The heating rate was maintained at $5^{\circ} \mathrm{C} / \mathrm{min}$ from $20^{\circ} \mathrm{C}$ to $250^{\circ} \mathrm{C}$. An important aspect while carrying out the DSC was that there was no time lag or delay when taking the DSC readings for the wet granulation sample and also for the humidity-treated granules (time bound experiment) to minimize errors in the results.

\section{Compression of Tablets}

Tablets were compressed for the end point granules with both the granulating fluids using a Carver ${ }_{\circledast}$ press (model\#2822, Fred S. Carver INC., Wabash, IN.. USA) at a compression force of $3000 \mathrm{lb}$. Tablets were subsequently tested for its hardness utilizing tablet tester 6D (Schleuniger Pharmatron, Inc., Manchester) and the values were noted.

\section{Data Analysis}

The raw data were treated and analyzed using the FT4 data analysis software version 4.0.14 (Freeman Technology Ltd, Tewkesbury, UK) 


\section{RESULTS}

\section{Thermal Effusivity Measurements}

As evident from (Fig. 2), the effusivity values for the wet granules formed using water as solvent showed a gradual increase up to $50 \% w / w$ binder solution. However, beginning $50 \% w / w$ binder solution, a steep increase in the effusivity value was observed, which ultimately led to the slurry formation at $65 \% w / w$ with values touching around $1647\left(\mathrm{Ws}^{1 / 2} / \mathrm{m}^{2} \mathrm{~K}\right)$.

A similar trend was followed for the effusivity values using ethanol/water $(80: 20)$ as solvent up to $50 \% \mathrm{w} / \mathrm{w}$ binder solution; a steep increase beginning $50 \% \mathrm{w} / \mathrm{w}$ and finally the slurry formation at $65 \%$, but values touching around 1050 $\left(\mathrm{Ws}^{1 / 2} / \mathrm{m}^{2} \mathrm{~K}\right)$.

Although $50 \% w / w$ binder solution was denoted as the end point for wet granulation in (water solvent) case, but a force overload detection of this batch while operating in the FT4 Rheometer led to $47.5 \% w / w$ binder solution as the final wet granulation end point for the purpose of rheological characterization. On the other hand, a force overload in the FT4 rheometer at $52.5 \% \mathrm{w} / \mathrm{w}$ binder solution (ethanol/water solvent) led to $50 \% w / w$ binder solution as the wet granulation end points for the same rationale as mentioned earlier.

\section{Measurement of Dynamic Properties (BFE, SE, and AE)}

\section{Wet Granules}

The BFE values for the wet granules (Fig. 3a) formed using both the granulating fluids were fairly low for the first two points. However, it showed an increasing trend with an increase in the percentage $w / w$ binder solutions in both cases. Furthermore, a sharp increase in the BFE (Fig. 3a) and SE (Fig. 3b) values at $47.5 \% w / w$ binder solution in case of (water solvent), and $50 \% w / w$ binder solution in case of (ethanol/ water solvent) was observed.

The SE values remained almost constant for the first two points and then soared as it reached the wet granulation end point in both the cases. As a general trend, the BFE and SE

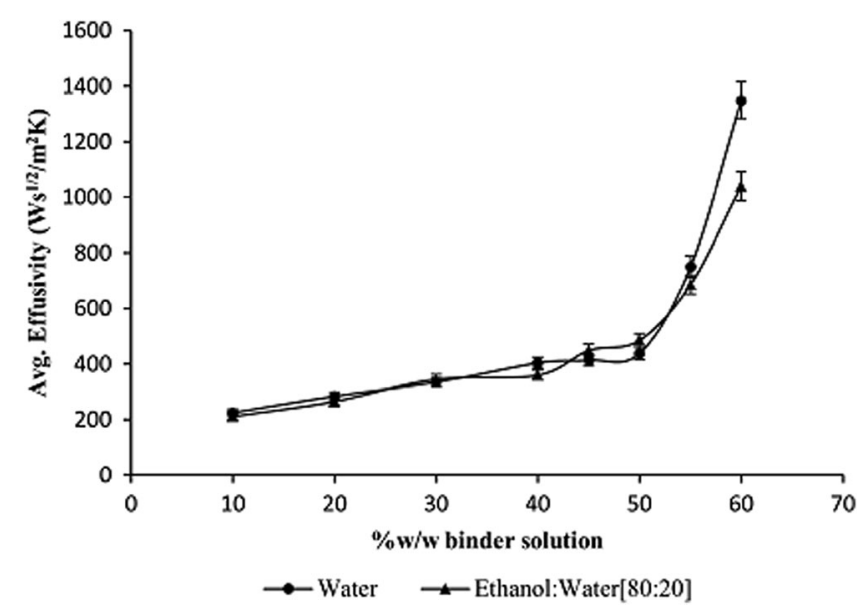

Fig. 2. Thermal Effusivity Measurements values obtained in case of (ethanol/water solvent) granules were comparatively quite high as compared to the (water solvent) granules.

\section{Dried Granules}

The BFE (Fig. 3c) and SE (Fig. 3d) follow the same trend as for the wet granules except that the values are significantly lower for the ethanol/water solvent.

As seen from Fig. $3 g$, the dried granules showed an increasing trend in the aeration energy with a proportionate increase in the percentage $w / w$ binder solutions in both cases. However, the increase in the case of water solvent granules is quite high as compared to the increase in the case of (ethanol/ water solvent) granules.

\section{Humidity-Treated End Point Granules}

These granules show little to no variation in the BFE (Fig. 3e) and the SE (Fig. 3f) values in both the cases.

\section{Measurement of Bulk Properties (Permeability and Compressibility)}

\section{Wet Granules}

As evident from Fig. 4a, higher initial Pressure Drop (PD) values were reported in both cases. However, with an increase in percentage $w / w$ binder solution, a steady decline in the PD values was observed

\section{Dried Granules}

The PD values for dried granules in both cases (Fig. 4b) followed the same pattern as obtained for the wet granules. Interesting results were obtained for the compressibility data. As shown in Fig. 4d, the percentage compressibility (CPS) values for water solvent granules showed a curvilinear trend, whereas the CPS values for the ethanol/water solvent granules showed no significant variation with the increase in the $(w / w)$ percentage binder solution.

\section{Humidity-Treated End Point Granules}

The PD values (Fig. 4c) and the CPS values (Fig. 4e) showed little to no variation on the permeability of the powder bed and compressibility, respectively, when exposed to different relative humidity conditions.

\section{Measurement of Shear Properties (Wall Friction Angle and Shear Stress)}

\section{Dried Granules}

An increasing trend in the wall friction angle (Fig. 5a) with an increase in the percentage $(w / w)$ binder solution was observed in both cases. The UYS (Fig. 5c) and cohesion values (Fig. 5d) increased significantly in both cases, and consequently, the $\mathrm{ff}_{\mathrm{c}}$ value decreased proportionately with an increase in the percentage $(w / w)$ binder solution. 

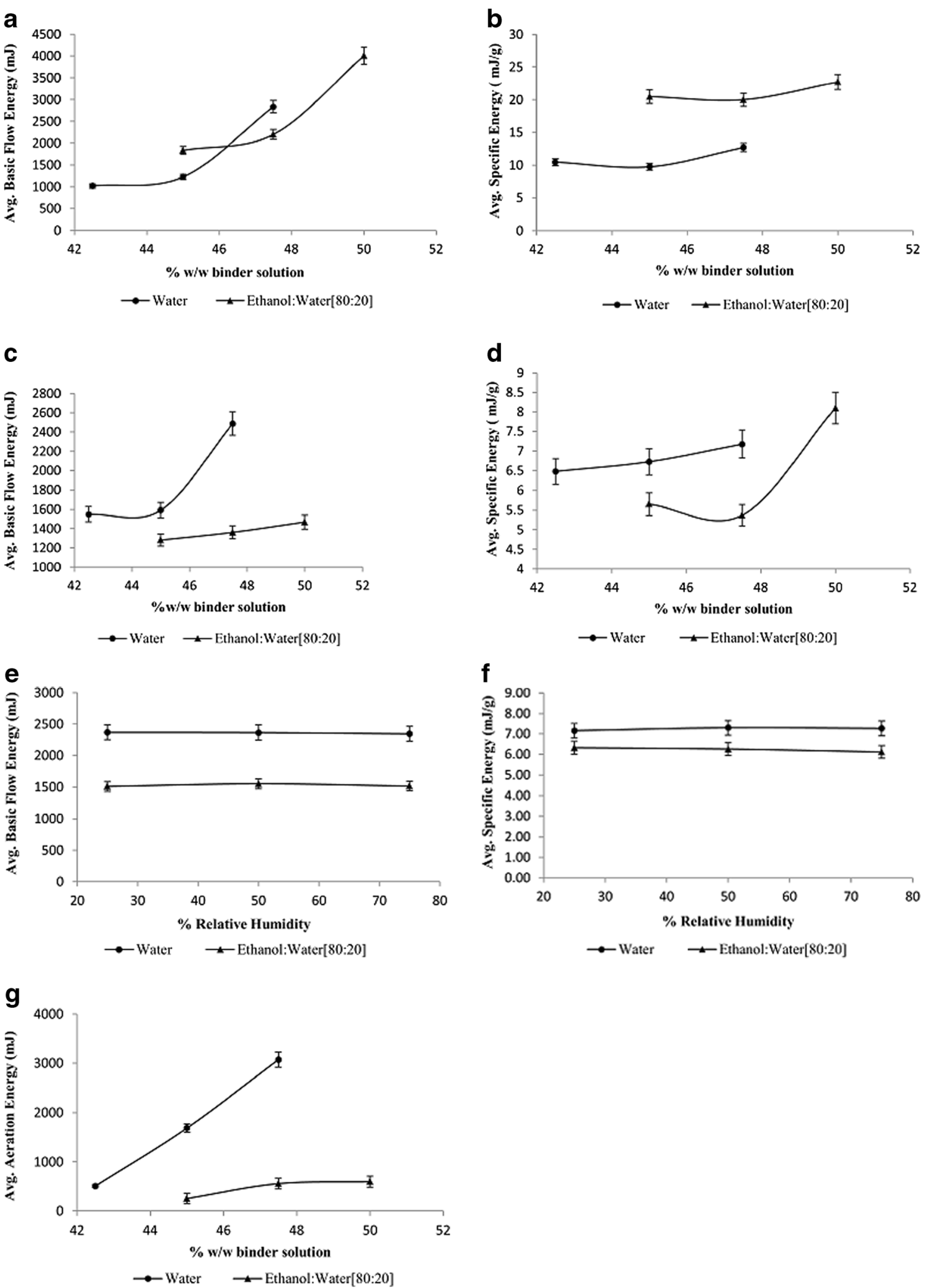

Fig. 3. a, b BFE and SE as a function of percentage $w / w$ binder solution, respectively [wet granules]. c, d BFE and SE as a function of percentage $w / w$ binder solution, respectively [dried granules]. e, f BFE and SE as a function of relative humidity, respectively [end point granules]. $\mathbf{g}$ Aeration energy as a function of percentage $w / w$ binder solution [dried granules] 


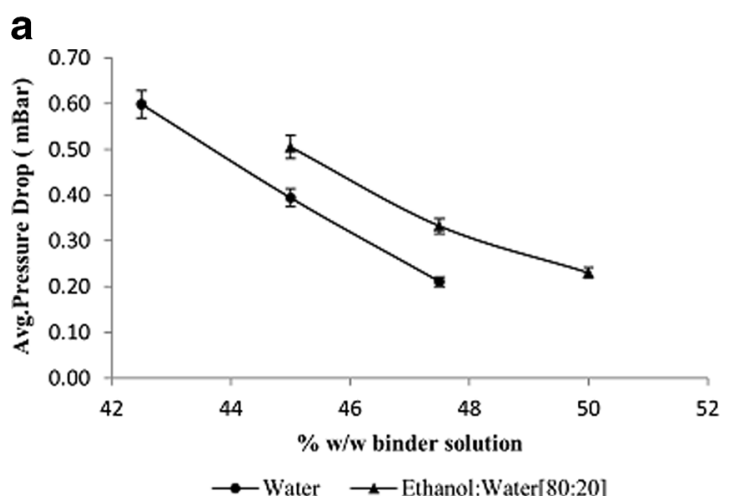

b
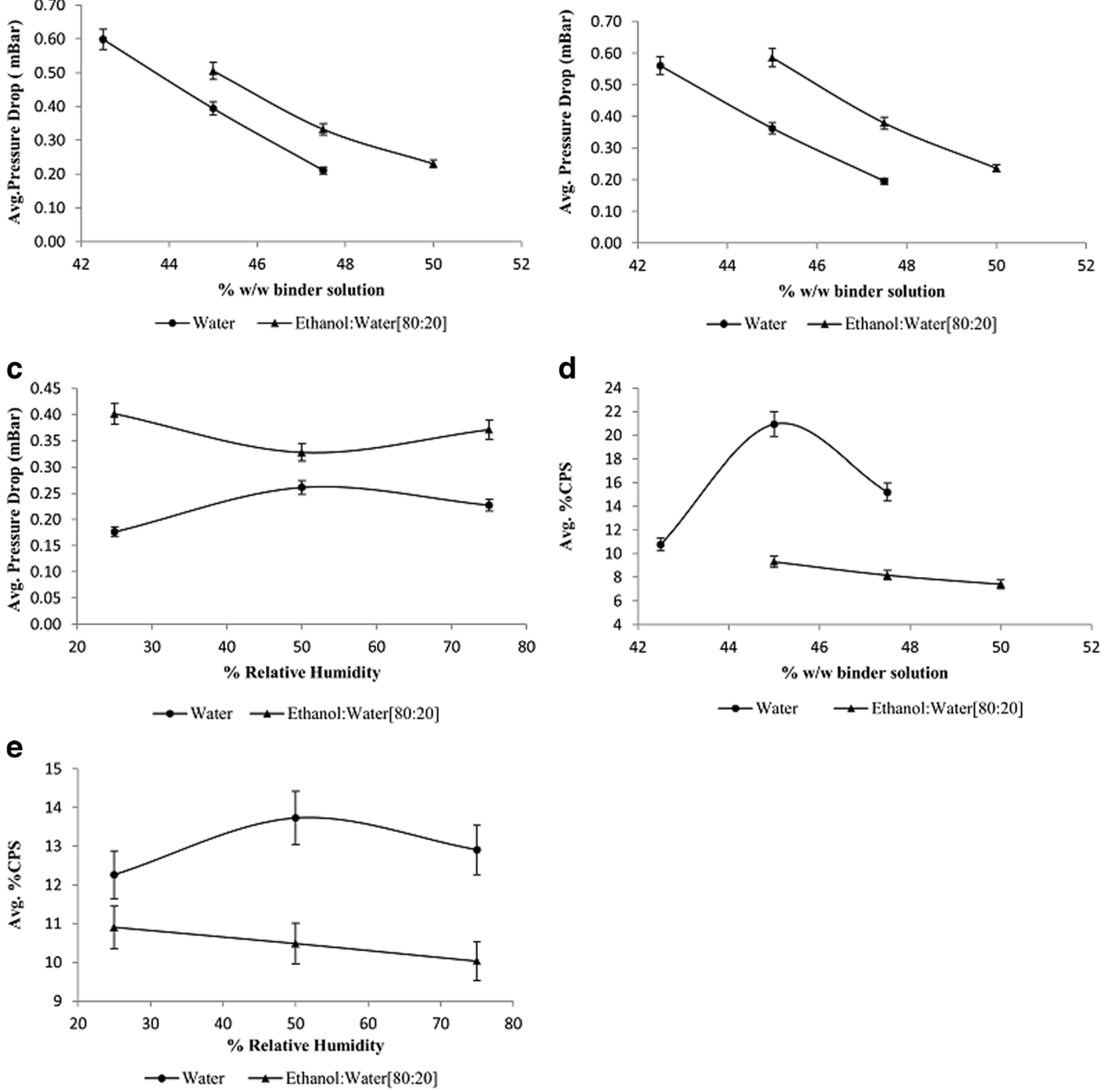

Fig. 4. a, b Permeability as a function of percentage $w / w$ binder solution [wet and dried granules, respectively]. c Permeability as a function of relative humidity [end point granules]. d Compressibility as a function of percentage $w / w$ binder solution [dried granules]. e Compressibility as a function of relative humidity [end point granules]

\section{Humidity-Treated End Point Granules}

The WFA values (Fig. 5b) were almost consistent with each other in both cases upon exposure to different relative humidity conditions. The UYS, cohesion, and $\mathrm{ff}_{\mathrm{c}}$ values (Fig. 5e, f) of the end point granules were hardly affected upon exposure to different relative humidity conditions.

\section{DSC Measurements}

\section{Wet Granules}

With an increasing concentration of the percentage $w / w$ binder solutions for (water solvent) granules (Fig. 6a), a proportionate increase in the sharpness of the endothermic peak was observed. The end point peak for these granules was obtained around $100^{\circ} \mathrm{C}$. On the other hand, for (ethanol/water solvent) granules (Fig. 6b), the endothermic peak remained constant for the first two points, but shot up for the end point peak around $70^{\circ} \mathrm{C}$.

\section{Humidity-Treated End Point Granules}

The enthalpy value of (water solvent) dried granules (control) (Fig. 6c), was found to be higher than the humidity-treated granules which decrease in the order of $75 \%>53 \%>22.5 \%$. On the other hand, the enthalpy value of (ethanol/water solvent) dried granules (control) (Fig. 6d), was found to be lower than the humidity-treated granules. 

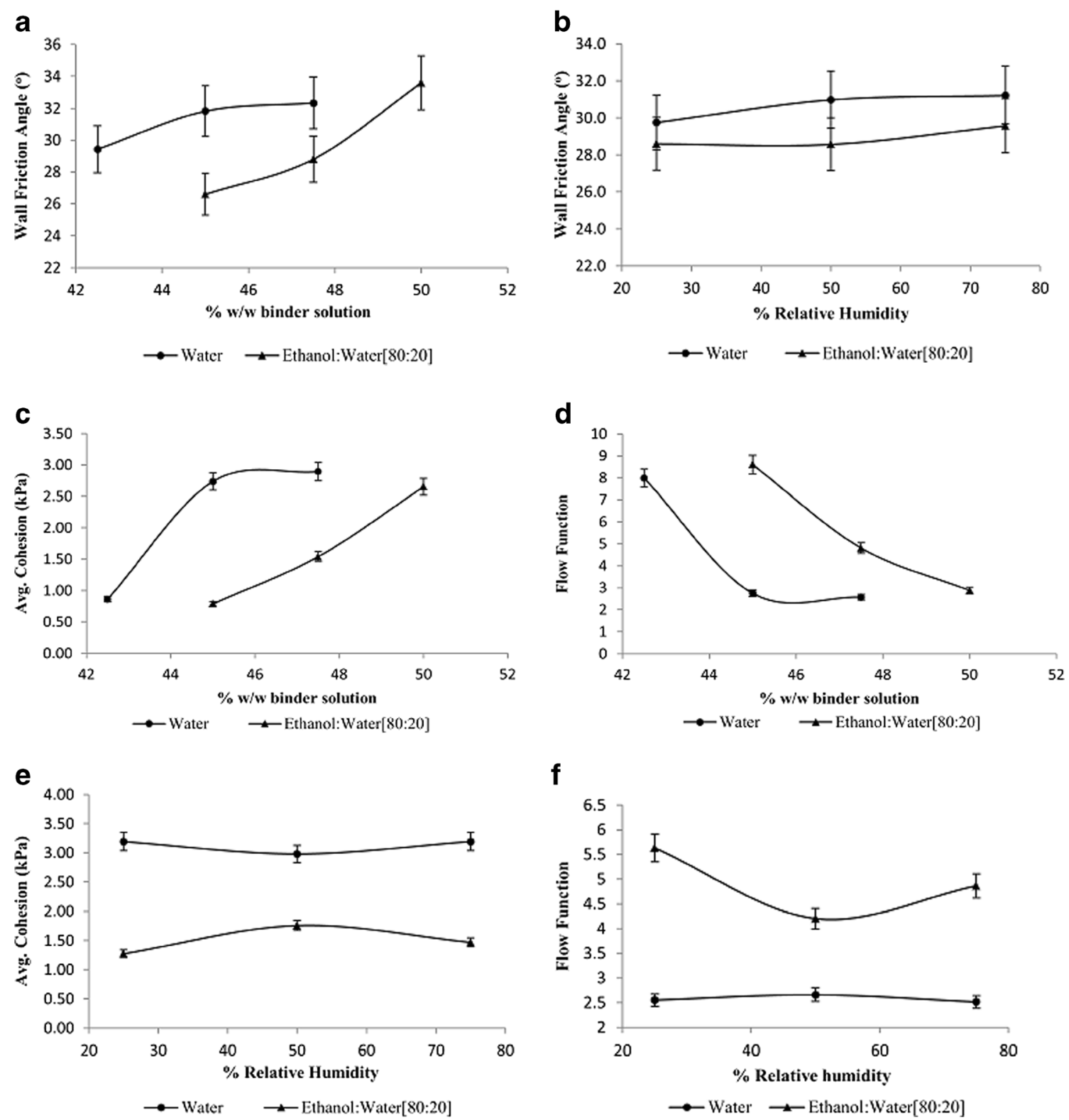

Fig. 5. a Wall friction angle as a function of percentage $w / w$ binder solution [dried granules]. b Wall friction angle as a function of relative humidity [end point granules]. c, $\mathbf{d}$ Cohesion and flow function as a function of percentage $w / w$ binder solution, respectively [dried granules]. e, $\mathbf{f}$ Cohesion and flow function as a function of relative humidity, respectively [end point granules]

\section{Tablet Hardness}

The tablets formed from the (water solvent) granules showed less hardness as compared to the ones from the (ethanol/water solvent) granules.

\section{DISCUSSION}

\section{Thermal Effusivity Analysis}

These measurements are mainly used as a tool to determine the wet granulation end point, and also provide a brief perspective of the batches to be made at a large-scale laboratory for the rheological assessment of powders. Considering water has an effusivity of $1600\left(\mathrm{Ws}^{1 / 2} / \mathrm{m}^{2} \mathrm{~K}\right)$, a slight addition of the binder solution produces a measurable effect on the effusivity readings. Density is also dependent on the particle size and the binder solution added. And the heat capacity values are also subject to changes based on the binder solution adsorbed (16).

As shown in (Fig. 2), the steep increase in the effusivity value beginning $50 \% \mathrm{w} / \mathrm{w}$ binder solution (water solvent) granules, suggests over-wetting of the granules. And the slurry formation at $65 \% w / w$ binder solution implies that the particles are being completely surrounded by water molecules, as the reading is representative of water $(48,49)$.

A similar explanation holds true for ethanol/water (80:20) as solvent, with the effusivity values at $65 \% \mathrm{w} / \mathrm{w}$ binder solution being illustrative of the hydroethanolic solvent. 

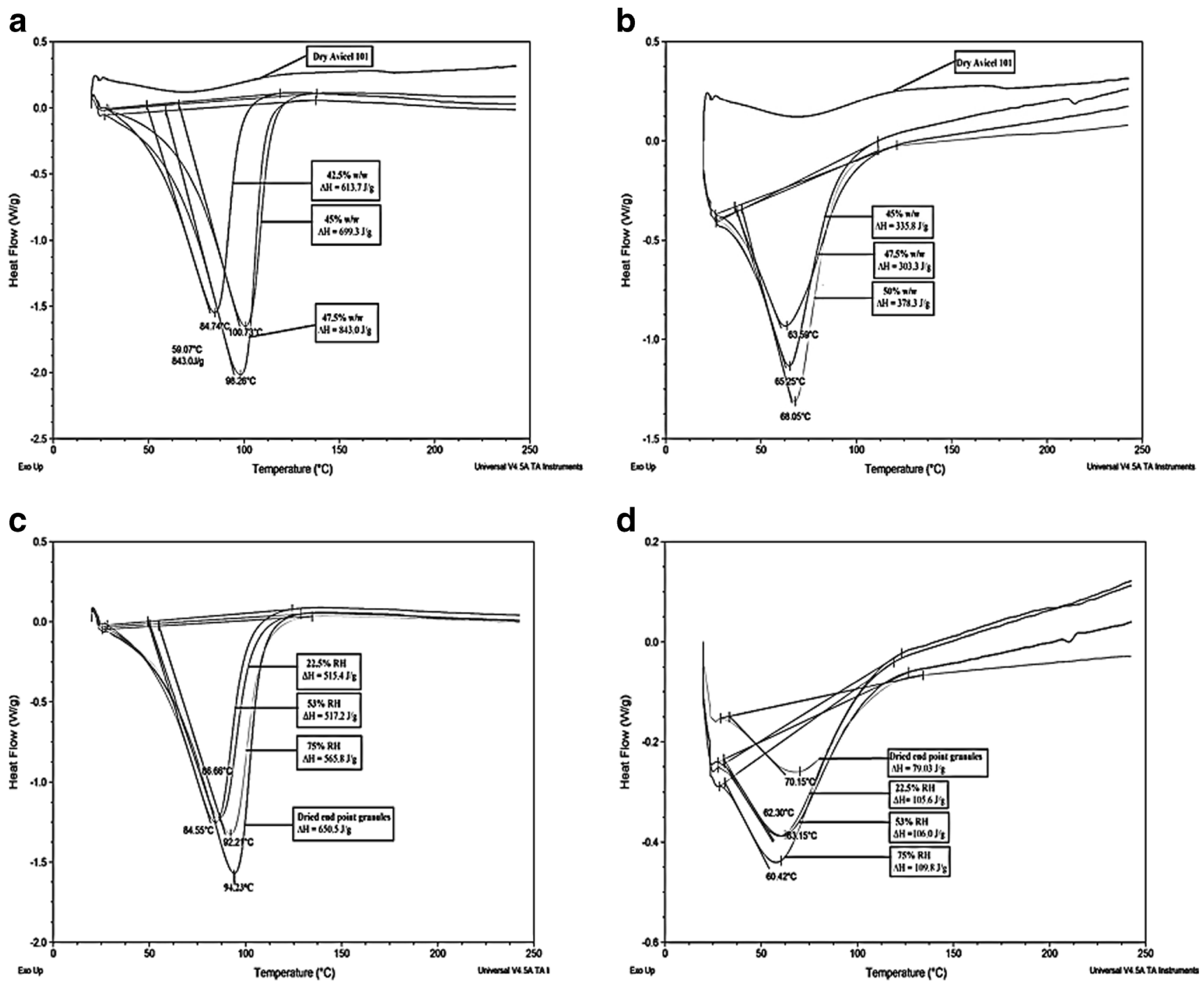

Fig. 6. a, b Comparison of the DSC thermograms of wet granules (water solvent batch) and (ethanol/water solvent batch), respectively. c, d Comparison of the DSC thermograms of dried and RH-exposed end point granules (water alone solvent batch) and (ethanol/water solvent batch), respectively

\section{Characterization of the Dynamic Properties (BFE, SE, and AE)}

\section{Wet Granules}

As seen from Fig. 3a, the lower BFE value of the first two points in both cases can be attributed to the fine cohesive powder resulting in a localized stress transmission zone. The sharp increase in the BFE (Fig. 3a) and SE (Fig. 3b) values at $47.5 \% \mathrm{w} / \mathrm{w}$ binder solution (water), and $50 \% \mathrm{w} / \mathrm{w}$ binder solution (ethanol/water mixture) corresponds to the transformation of the dry powder to granules which is further confirmed by the visual difference of the resultant products. The granules thus formed pack themselves efficiently and show significant adhesive property, thereby offering considerable resistance to the flow. The resulting high number of friction surfaces and high-contact stresses contribute substantially to the high BFE reading at the end point of wet granulation $(37,42)$.
The massive difference in the readings of BFE and SE in case of (ethanol/water solvent) granules as compared to the (water solvent) granules corresponds to the hygroscopic nature of MCC PH-101 (50,51). The high propensity of MCC towards water than ethanol/water solvent results in the latter floating on the surface of the powder, thus favoring more particle to particle friction and cohesion, and ultimately more resistance to the flow.

\section{Dried Granules}

As seen from (Fig. 3c, d), a significantly lower BFE and $\mathrm{SE}$ values for (ethanol/water solvent) dried granules reflects that the solvent is not being entrapped by MCC due to its low proclivity towards the same as opposed to (water solvent) dried granules.

The higher increase in $\mathrm{AE}$ in case of (water solvent) granules as compared to the (ethanol/water solvent) granules can be accredited to more cohesive forces still 
existing between the former granules due to the hygroscopic nature of MCC $(50,52)$. This prohibits the complete separation of particles and the air channels or flows through the bulk of the powder. Besides cohesion, the density of the granules also plays a vital role in the aeration process. Since the density of water is more than ethanol, and the fact that equal volumes of the sample were taken during testing, the granules formed from water solvent are denser than the granules formed from ethanol/ water solvent hence requiring more aeration energy for them to be lifted as opposed to the lighter ethanol/water granules.

\section{Humidity-Treated End Point Granules}

The little to no variation in the BFE (Fig. 3e) and the SE (Fig. 3f) values in both cases, suggests no change in the flow energies of the granules upon exposure to different relative humidity conditions.

\section{Characterization of Bulk Properties (Permeability and Compressibility)}

\section{Wet Granules}

The initial high PD value in both cases (Fig. 4a), represents what predominantly are fines which provide more resistance for the air to pass through the bulk, thus making it less permeable. And the steady decline in PD values in both cases with an increase in percentage $w / w$ binder solution can be attributed to the formation of granules. These granules pack themselves in a way that promotes the efficient flow of air through them and hence, lesser values.

\section{Dried Granules}

The similar pattern of the PD values of dried granules as that of wet granules again reflects that the granules offer less resistance to the air flow as they approach the granulation end point.

\section{Humidity-Treated End Point Granules}

Almost unaffected PD (Fig. 4c) and CPS (Fig. 4e) values in both cases, suggests that the permeability and compressibility of the granules are impervious to the different relative humidity conditions.

\section{Characterization of Shear Properties (Wall Friction Angle \& Shear Stress)}

\section{Dried Granules}

As shown in (Fig. 5a), the gradual increase in the WFA with an increase in the percentage $(w / w)$ binder solution in both cases, attributes to the greater shear stress required to overcome the increasing cohesive forces and finally reach the incipient failure.

As evident from (Fig. 5c, d), the increasing UYS and cohesion values upon addition of more of the binder solution attributes to the increasing resistance to fail (break) the bed.
This increase in resistance reflects greater frictional and cohesive forces between the powder particles. The decline in the $\mathrm{ff}_{\mathrm{c}}$ value indicates that the particular powder sample flows with less ease when subjected to the same stress conditions, further confirming the increase in cohesivity of the powder bed.

\section{Humidity-Treated End Point Granules}

As indicated in (Fig. 5b, e, f) almost consistent WFA, UYS, cohesion, and $\mathrm{ff}_{\mathrm{c}}$ values in both cases, suggest that the different relative humidity conditions did not impact the cohesive forces among the granules significantly (30).

\section{DSC Analysis}

\section{Wet Granules}

As shown in (Fig. 6a), the proportionate increase in the sharpness of the endothermic peak with an increase in concentration of the percentage $w / w$ binder solution for (water solvent) granules suggests an increase in the enthalpy values found by integrating the peaks (52). And the appearance of end point peak around $100^{\circ} \mathrm{C}$ reflects that water is no longer retained inside the granules but appears on the surface, thus further confirming the wet granulation end point (16). A similar explanation holds true for the end point endothermic peak obtained around $70^{\circ} \mathrm{C}$ for (ethanol/water solvent) granules.

\section{Humidity-Treated End Point Granules}

As indicated in (Fig. 6c), the higher enthalpy values for (water solvent) dried granules (control) than the humidity-treated granules could possibly be explained by the fact that the dried end point granules still have some entrained water molecules owing to the hygroscopicity of MCC (53), corresponding to an enthalpy of $(650.5 \mathrm{~J} / \mathrm{g})$. Because the humidity chamber works on the principle of equilibration of the moisture content inside the granules and the ambient environment (54), the $75 \% \mathrm{RH}$ chamber results in comparative less loss of water molecules from the powder to the inside environment as opposed to the $53 \% \mathrm{RH}$ and the $22.5 \% \mathrm{RH}$ chambers; thereby meaning more moisture still entrapped in the granules exposed to the $75 \% \mathrm{RH}$, which is evident from its higher enthalpy value. But the enthalpy difference for the three RH conditions cannot be accounted for a significant change.

Figure $6 \mathrm{~d}$ represents the humidity-treated end point granules (ethanol/water solvent). Owing to the absence of any entrapped water molecules, the granules, while attaining the equilibrium moisture absorb some of the water molecules from the inside environment into the granules. Although, the enthalpy value for the \% RH conditions shows a slight rise than for the dried granules, the values remained almost constant for the three different \% RH conditions, suggesting little to no effect of the $\% \mathrm{RH}$ on the granules.

\section{Tablet Hardness Analysis}

From Table I, it is very much evident that the tablets formed from the water solvent granules showed less hardness, 
Table I. Tablet Hardness as a Function of $\% w / w$ Binder Solution

\begin{tabular}{llll}
\hline Solvent used & $\begin{array}{l}\text { \% } w / \mathrm{w} \\
\text { Binder solution }\end{array}$ & $\begin{array}{l}\text { Hardness } \\
(\mathrm{kPa})\end{array}$ & $\%$ RSD \\
\hline Water & 42.5 & 11.30 & 2.31 \\
& 45 & 9.26 & 3.78 \\
Ethanol/water & 47.5 & 12.42 & 2.11 \\
[80:20] & 45 & 35.72 & 1.86 \\
& 47.5 & 34.44 & 2.52 \\
& 50 & 35.52 & 1.97 \\
\hline
\end{tabular}

$R S D$ relative standard deviation

as compared to the ones from the ethanol/water solvent granules. A possible explanation to this difference in the hardness property can be attributed to the fact that MCC, being hygroscopic in nature, still has some entrapped water molecules as it forms irreversible hydrogen bonding with water (55). As a result of this, there is less number of $-\mathrm{H}$ group available to form new bonds. Since the bonding strength of MCC is more in water granules as compared to those with ethanol/water granules, therefore, the water granules show poor compressibility and compactibility, which thus leads to lower tablet hardness $(56,57)$. Ethanol/water $(80: 20)$ as solvent on the other hand completely evaporates, thus imparting more hardness to the tablets.

\section{CONCLUSION}

The TC probe and the FT4 powder rheometer can together be used as a tool to determine the optimum wet granulation end point. The flow properties of the granules still remain a complex science depending upon a number of factors, such as shear strength, compressibility, cohesiveness, air content, and other parameters. The above study concludes that the granulating fluids play a vital role in the wet granulation end point and also on the dynamic, bulk, and shear properties of the granules in case of HPMC as the binder for MCC, which would further help the formulation scientists to gain better insight into the granulating fluid selection and determining the end point of wet granulation. Also, a positive correlation between the FT4 rheometer and the DSC data for the humidity-exposed granules suggested little or no effect on the rheological properties, thereby providing better acumen for determining the optimum storage conditions for granules used in the pharmaceutical industry.

\section{REFERENCES}

1. Parikh DM. Handbook of pharmaceutical granulation technology. CRC Press; 1997.

2. Ennis B. Theory of granulation: an engineering perspective. Handbook of pharmaceutical granulation technology. Taylor and Francis Group; 2006.

3. Chitu TM, Oulahna D, Hemati M. Wet granulation in laboratory scale high shear mixers: effect of binder properties. Powder Technol. 2011;206(1):25-33.

4. Sakr WF, Ibrahim MA, Alanazi FK, Sakr AA. Upgrading wet granulation monitoring from hand squeeze test to mixing torque rheometry. Saudi Pharm J. 2012;20(1):9-19.

5. Shirakura O, Yamada M, Hashimoto M, Ishimaru S, Takayama K, Nagai T. Effect of amount and composition of granulating solution on physical characteristics of tablets. Drug Dev Ind Pharm. 1992;18(10):1099-110.

6. Wells JI, Walker CV. The influence of granulating fluids upon granule and tablet properties: the role of secondary binding. Int J Pharm. 1983;15(1):97-111.

7. Darunkaisorn W, Mahadlek J, Phaechamud T. HPMC matrix granule formation: selection of suitable granulating fluid. Thai Pharm Health Sci J. 2009;4(1):29-45.

8. Unvala HM, Schwartz JB, Schnaare RL. The effect of the wet granulation process on drug dissolution. Drug Dev Ind Pharm. 1988;14(10):1327-49.

9. Zhao N, Augsburger LL. The influence of granulation on super disintegrant performance. Pharm Dev Technol. 2006;11(1):47-53.

10. Mehrotra A, Chaudhuri B, Faqih A, Tomassone M, Muzzio F. A modeling approach for understanding effects of powder flow properties on tablet weight variability. Powder Technol. 2009;188(3):295-300.

11. Michaels JN, Farber L, Wong GS, Hapgood K, Heidel SJ, Farabaugh J, et al. Steady states in granulation of pharmaceutical powders with application to scale-up. Powder Technol. 2009;189(2):295-303.

12. Levin M. Wet granulation: end-point determination and scale-up. New York: Encyclopedia of pharmaceutical technology; 2006. p. 4078-98.

13. Frake P, Greenhalgh D, Grierson S, Hempenstall J, Rudd D. Process control and end-point determination of a fluid bed granulation by application of near infra-red spectroscopy. Int J Pharm. 1997;151(1):75-80.

14. Corvari V, Fry WC, Seibert WL, Augsburger L. Instrumentation of a high-shear mixer: evaluation and comparison of a new capacitive sensor, a watt meter, and a strain-gage torque sensor for wet granulation monitoring. Pharm Res. 1992;9(12):1525-33.

15. Watano S, Tanaka T, Miyanami K. A method for process monitoring and determination of operational end-point by frequency analysis of power consumption in agitation granulation. Adv Powder Technol. 1995;6(2):91-102.

16. Dave RH, Wu SH, Contractor LD. To determine the end point of wet granulation by measuring powder energies and thermal properties. Drug Dev Ind Pharm. 2012;38(4):439-46.

17. Fariss G, Keintz R, Okoye P. Thermal effusivity and power consumption as: PAT tools for monitoring granulation end point. Pharm Technol. 2006;30(6).

18. Cantor SL, Augsburger LL, Hoag SW, Gerhardt A. Pharmaceutical granulation processes, mechanism and the use of binders. Pharm Dosage Forms Tablets. 2008;1:261-302.

19. Ethers MC. Technical handbook. Midland: Dow Chemical Company; 1997.

20. Cellulose M. Technotes. Midland: Dow Chemical Company; 2003.

21. Ennis BJ, Tardos G, Pfeffer R. A microlevel-based characterization of granulation phenomena. Powder Technol. 1991;65(1):257-72.

22. Knowlton TM, Klinzing G, Yang W, Carson J. The importance of storage, transfer, and collection. Chem Eng Progress (United States). 1994;90(4).

23. Teunou E, Fitzpatrick J. Effect of relative humidity and temperature on food powder flowability. J Food Eng. 1999;42(2):109-16.

24. Guerin E, Tchoreloff P, Leclerc B, Tanguy D, Deleuil M, Couarraze G. Rheological characterization of pharmaceutical powders using tap testing, shear cell and mercury porosimeter. Int J Pharm. 1999;189(1):91-103.

25. Fitzpatrick J, Barringer S, Iqbal T. Flow property measurement of food powders and sensitivity of Jenike's hopper design methodology to the measured values. J Food Eng. 2004;61(3):399-405.

26. Chapter G. 1174> Powder flow. USP33-NF28. 2010.

27. Shah RB, Tawakkul MA, Khan MA. Comparative evaluation of flow for pharmaceutical powders and granules. AAPS PharmSciTech. 2008;9(1):250-8.

28. Carr RL. Evaluating flow properties of solids. Chem Eng. 1965;72(2):163-8.

29. Hausner H. Friction conditions in a mass of metal powder. Los Angeles: Polytechnic Inst. of Brooklyn. Univ. of California; 1967.

30. Jenike AW. Storage and flow of solids. In: Utah Uo, editor. November 1964 (Revised 1980). 
31. Ramachandruni H, Hoag SW. Design and validation of an annular shear cell for pharmaceutical powder testing. J Pharm Sci. 2001;90(5):531-40.

32. Hancock BC, Vukovinsky KE, Brolley B, Grimsey I, Hedden D, Olsofsky A, et al. Development of a robust procedure for assessing powder flow using a commercial avalanche testing instrument. J Pharm Biomed Anal. 2004;35(5):979-90.

33. Faqih A, Chaudhuri B, Alexander AW, Davies C, Muzzio FJ, Tomassone MS. An experimental/computational approach for examining unconfined cohesive powder flow. Int J Pharm. 2006;324(2):116-27.

34. Abraham D, George K, Francis DJ. Rheological characterization of blends of low density with linear low density polyethylene using a torque rheometer. Eur Polym J. 1990;26(2):197-200.

35. Zatloukal Z, Sklubalova Z. Penetrometry and estimation of the flow rate of powder excipients. Die Pharmazie-An Int J Pharm Sci. 2007;62(3):185-9.

36. Weth M, Hofmann M, Kuhn J, Fricke J. Measurement of attractive forces between single aerogel powder particles and the correlation with powder flow. J Non-Cryst Solids. 2001;285(1):23643.

37. Freeman R. Measuring the flow properties of consolidated, conditioned and aerated powders-a comparative study using a powder rheometer and a rotational shear cell. Powder Technol. 2007;174(1):25-33.

38. Trivedi MR, Dave RH. To study physical compatibility between dibasic calcium phosphate and cohesive actives using powder rheometer and thermal methods. Drug Dev Ind Pharm. 2013;112.

39. Chaudhari SP, Dave RH. To prepare and characterize microcrystalline cellulose granules using water and isopropyl alcohol as granulating agents and determine its end-point by thermal and rheological tools. Drug Dev Ind Pharm. 2014;1-9.

40. Wexler A, Hasegawa S. Relative humidity-temperature relationships of some saturated salt solutions in the temperature range 0 to 50 C. Precision Measurements and Calibrations Bloss RL, Orloski MJ, editors. Government Printing Office, Washington, DC, NBS Special Publication. 1972;300(8):287-94.

41. Greenspan L. Humidity fixed points of binary saturated aqueous solutions. J Res Natl Bur Stand A Phys Chem A. 1977;81:89-96.

42. Reg Freeman TFBA. The characterisation of the physical properties of wet masses Powder Technology 174. 2007:25-33.

43. Navaneethan CV, Missaghi S, Fassihi R. Application of powder rheometer to determine powder flow properties and lubrication efficiency of pharmaceutical particulate systems. AAPS PharmSciTech. 2005;6(3):E398-404.
44. Freeman TC, Freeman RE, Armstrong B. The characterisation of powder and bulk material-a multivariate approach using dynamic, shear and bulk property measurements. 2011.

45. Berry R, Bradley M, McGregor R. Brookfield powder flow tester-results of round robin tests with CRM-116 limestone powder. Proc Inst Mech Eng E J Process Mech Eng. 2014;0954408914525387.

46. Schulze D. Powders and bulk solids: behavior, characterization, storage and flow: Springer. 2007.

47. Schwedes J. Review on testers for measuring flow properties of bulk solids. Granul Matter. 2003;5(1):1-43.

48. Ghorab MK, Chatlapalli R, Hasan S, Nagi A. Application of thermal effusivity as a process analytical technology tool for monitoring and control of the roller compaction process. AAPS PharmSciTech. 2007;8(1):E155-61.

49. Roy Y, Closs S, Mathis N, Nieves E. Process analytical technology - thermal effusivity as a process analytical technology to optimize, monitor, and control fluid-bed drying - the authors point out the advantages and disadvantages of. Pharmaceutical Technology. 2004;28(9):S21

50. Rowe RC, Sheskey PJ, Quinn ME, Press P. Handbook of pharmaceutical excipients. London: Pharmaceutical press; 2009.

51. Sun CC. Mechanism of moisture induced variations in true density and compaction properties of microcrystalline cellulose. Int J Pharm. 2008;346(1):93-101.

52. Szakonyi G, Zelkó R. The effect of water on the solid state characteristics of pharmaceutical excipients: Molecular mechanisms, measurement techniques, and quality aspects of final dosage form. Int J Pharm Investig. 2012;2(1):18.

53. Ardizzone S, Dioguardi F, Mussini T, Mussini P, Rondinini S, Vercelli B, et al. Microcrystalline cellulose powders: structure, surface features and water sorption capability. Cellulose. 1999;6(1):57-69.

54. Callahan J, Cleary G, Elefant M, Kaplan G, Kensler T, Nash R. Equilibrium moisture content of pharmaceutical excipients. Drug Dev Ind Pharm. 1982;8(3):355-69.

55. Buckton G, Yonemochi E, Yoon W, Moffat A. Water sorption and near IR spectroscopy to study the differences between microcrystalline cellulose and silicified microcrystalline cellulose before and after wet granulation. Int J Pharm. 1999;181(1):41-7.

56. Leuenberger H, Rohera BD. Fundamentals of powder compression. I. The compactibility and compressibility of pharmaceutical powders. Pharm Res. 1986;3(1):12-22.

57. Dawoodbhai S, Rhodes CT. The effect of moisture on powder flow and on compaction and physical stability of tablets. Drug Dev Ind Pharm. 1989;15(10):1577-600. 